\title{
Microbiological Studies on Naturally Present Bacteria in Camel and Buffalo Milk
}

\author{
Amr M. Abdou*, Riham H. Hedia, Shimaa T. Omara, Mai M. Kandil, M. A. Bakry and Mohammad M. Effat \\ Department of Microbiology and Immunology, National Research Centre 12622 Dokki, Giza, Egypt \\ *Corresponding author's Email: amrkheir@yahoo.com; (iDORCiD: 0000-0002-3373-2406
}

\begin{abstract}
The aim of current study was to isolate and identify naturally occurring probiotic Lactobacillus species in buffalo milk, camel milk, and camel urine to investigate their susceptibility to antibiotics and their antibacterial activity against pathogenic bacteria. A total number of seven samples which included three milk samples from buffalo, three milk samples from camel, and one urine sample from camel were collected and used in this study. The samples were cultured, and 18 isolated strains were identified by using 16S rRNA multiplex Polymerase Chain Reaction analysis, which was performed following DNA extraction from the isolated bacteria. Buffalo and camel milk were different in their Lactobacilli content. All Lactobacilli strains that were found in both camel milk and camel urine, were also found in buffalo milk, Lactobacilli strains in camel milk and urine were generally more resistant to the antibiotic. Lactobacilli isolated from buffalo milk, camel milk, and also camel urine presented variable degrees of antibacterial activity against pathogenic bacteria. Further studies should be conducted with more samples to gain more information in the field of antibacterial activity of probiotic lactobacilli and to understand the mechanisms of their activity. Hopefully, they can be used as natural alternatives instead of synthetic antibiotics.
\end{abstract}

Keywords: Antibacterial, Antibiotics, Lactobacillus, Probiotics

\section{INTRODUCTION}

Antibiotic resistance is considered as a global health crisis threatening the lives of both humans and animals. Many clinically isolated pathogenic bacteria are becoming increasingly resistant to antibiotics and disinfectants which make infection of these bacteria difficult to treat. During their evolution, bacteria have been developing several sophisticated mechanisms of antibiotic resistance to all types of antibiotics with no exception (Davies and Davies, 2010). The growing threat of antibiotic resistance necessitates the employment of creative approaches towards the discovery of novel alternatives to antibiotics. The use of probiotics is one of the options that is being discussed by the medical community to be used as an alternative to antibiotics (Brunel and Guery, 2017).

Probiotics are living microorganisms which confer health benefits to the host upon their administration in suitable amounts (FAO/WHO, 2011). The beneficial balance of the intestinal microbiota is one of the health-promoting properties that can be presented by probiotic microorganisms. Probiotics have been prescribed for patients with gastrointestinal disease and complaints (Williams et al., 2010). There is a set of cumulative evidence that supports the use of probiotics, both in food products and supplements to provide protection against infectious diseases including respiratory infections (Hao et al., 2011; Ozen et al., 2015). Lactobacilli, Enterococci, and Bifidobacteria are families of Lactic Acid Bacteria (LAB) and they constitute the most frequently used strains of probiotics (Fijan, 2014). The LAB constitute a diverse group of microorganisms that are naturally present in human diet and in both gastrointestinal and urogenital tract of animals (Ruiz Rodriguez et al., 2019) The main objective of the current study was to isolate and identify naturally occurring probiotic Lactobacilli in buffalo milk as well as camel milk and urine to investigate their susceptibility to antibiotics as well as their antibacterial activity against representative pathogenic bacterial strains of both Gram-positive and Gram-negative bacteria to assess their potential use as natural alternatives to synthetic antibiotics.

\section{MATERIALS AND METHODS}

\section{Ethical approval}

Institutional Animal Ethics Committee, local laws and regulations were considered in performing our experiment. All procedures involving the use of the animals were approved by the ethics committee of National Research Centre, Egypt.

\section{Sample collection}

A total number of seven samples including three milk samples from three different buffalos, three milk samples from three different camels and one urine sample from a separate camel were collected during the summer of 2016 from 
private, individually owned healthy animals in Giza governorate, Egypt. The samples were collected under aseptic conditions in sterile containers and stored on ice. Lactobacillus spp. was isolated from the collected samples by using MRS medium as a selective medium. An amount of $1 \mathrm{ml}$ of each of the milk samples as well as $1 \mathrm{ml}$ of the urine sample was dissolved in $100 \mathrm{ml}$ of MRS broth ( $\mathrm{pH} \mathrm{6.5)}$ and incubated at $37{ }^{\circ} \mathrm{C}$ for $24 \mathrm{~h}$ in aerobic condition. The initial cultures were subcultured for seven times at $37{ }^{\circ} \mathrm{C}$ under low $\mathrm{pH}(\mathrm{pH} 4.5)$ and anaerobic condition in the presence of $10 \% \mathrm{CO}_{2}$ to eliminate unwanted bacteria. Single colonies were selected and streaked onto MRS agar media at $\mathrm{pH} 4.8$ to obtain pure colonies. Finally, single pure colonies of Lactobacillus were selected for further characterization and identification (Shokryazdan et al., 2014).

\section{Characterization of isolated bacteria}

The isolated bacteria were evaluated by different biochemical and molecular tests including Gram stain and Catalase test as well as bacterial morphology. The isolate bacteria were identified as Lactobacilli based on being Grampositive, Catalase-negative and having rod-shape under light microscope. The Lactobacilli identification of isolated bacteria were further confirmed by using $16 \mathrm{~S}$ rRNA multiplex polymerase chain reaction (PCR) analysis.

\section{Gram staining}

A prepared smear of $24 \mathrm{~h}$ cultured bacteria was heat fixed on a slide. Gram staining based on standard technique was then performed and then slides were observed under light microscope (Bergey et al., 1994).

\section{Catalase test}

Fresh liquid cultures which contained overnight grown cultures from selected single colonies were used for Catalase test. An amount of 3\% hydrogen peroxide solution was dropped onto $1 \mathrm{ml}$ of the culture. The formation of gas bubbles was considered as positive Catalase test and these samples were neglected while the other samples with negative Catalase test were selected since Lactobacilli are known to be Catalase-negative.

\section{Molecular identification of probiotic strains}

The DNA was extracted from the isolated bacteria and Lactobacillus strains were confirmed by using 16S rRNA multiplex PCR analysis (Kwon et al., 2004). The reaction mixture $(25 \mu \mathrm{l})$ contained $12.5 \mu \mathrm{l}$ of PCR Master Mix, $5 \mu \mathrm{l}$ primer mixture comprising $50 \mathrm{pmol}$ of each primer, $4.5 \mu \mathrm{l}$ of water, and $3 \mu \mathrm{l}$ of DNA template. PCR amplification was performed in Applied Biosystem 2720 thermal cycler, and DNA fragments were amplified as follows. Initial heating at $94{ }^{\circ} \mathrm{C}$ for $2 \mathrm{~min}, 35$ cycles consisting of denaturation at $94{ }^{\circ} \mathrm{C}$ for $20 \mathrm{sec}$, annealing at $51{ }^{\circ} \mathrm{C}$ for 40 sec, extension at 68 ${ }^{\circ} \mathrm{C}$ for $30 \mathrm{sec}$, and final extension step in $7 \mathrm{~min}$ at $68{ }^{\circ} \mathrm{C}$. The PCR products were separated on $1.5 \%$ agarose gel by electrophoresis and analyzed by RedSafe Nucleic Acid Staining Solution (Intron Biotechnology, Korea).

\section{Antibiotic susceptibility of Lactobacilli}

A wide panel of 14 antibiotic disks was tested against 7 mixed cultures of probiotic Lactobacilli isolated from both buffalo and camel samples (Figures 2-8). Antibiotic susceptibility test was performed by using the disk-diffusion method with some modifications (ISO, 2010). Lactobacilli activated cultures were swabbed on MRS agar plates instead of Muller Hinton Agar plates. Fourteen different antibiotic disks were used for the susceptibility test including Trimethoprim/sulfamethoxazole (SXT-25), Ofloxacin (OFX5), Cefuroxime (CXM-30), Amoxicillin with clavulanic acid (AmC-30), Cefotaxime (CTX-30), Cefaclor (CEC-30), Rifampicin (RD-5), Erythromycin (E-15), Vancomycin (Va-30), Amikacin (AK-30), Ampicillin with sulbactam (SAM-20), Cefadroxil (CFR-30), Azithromycin (AZM-15), and Doxycycline (DO-30). All plates were incubated for $24 \mathrm{~h}$ at $37^{\circ} \mathrm{C}$ and inhibition zones were measured.

\section{Antibacterial activity of Lactobacilli}

The ability of the seven mixed cultured of isolated probiotic Lactobacilli to inhibit the growth of pathogenic bacteria was investigated against nine pathogenic standard strains of both Gram-positive and Gram-negative bacteria (Figures 9-15). Gram-positive strains were represented by Staphylococcus aureus (ATCC 26923), Staphylococcus aureus (ATCC 29213), Staphylococcus epidermidis (ATCC 12228), Streptococcus pneumoniae (ATCC 29619), and Enterococcus faecalis ATCC (29212). Gram- negative strains were represented by Pseudomonas aeruginosa ATCC (27853), Escherichia coli ATCC (25922), Escherichia coli ATCC (10536), and Klebsiella pneumoniae ATCC (700603). Antibacterial activity of probiotic Lactobacilli was tested by using Agar-well diffusion method with some modifications (Bauer et al., 1966; Sgouras et al., 2004). Wells of $7 \mathrm{~mm}$ diameter were made on Muller-Hinton agar plates. Each plate was swabbed with the respective test pathogen. From each probiotic Lactobacillus strain which previously incubated under anaerobic conditions for $24 \mathrm{~h}$ at $37^{\circ} \mathrm{C}, 70 \mu \mathrm{l}$ of MRS liquid culture were placed in the respective wells. After $24 \mathrm{~h}$ of incubation at $37^{\circ} \mathrm{C}$, the inhibition zones were measured and recorded in $\mathrm{cm}$.

\section{Statistical analysis}


The in vitro antibacterial activity was conducted in triplicate. All the data were then subjected to SPSS Version 21 (IBM, New York, US). Statistical analysis was performed using two-way ANOVA followed by Duncan's Multiple Range Test to determine significant difference. The given values represented mean \pm Standard Deviation (SD). A probability value $\mathrm{P}<0.05$ was taken as significant difference (Steel and Torrie, 1980).

\section{RESULTS AND DISCUSSION}

Lactobacilli isolated from buffalo milk, camel milk, and camel urine were subjected to characterization and identification by using different biochemical and molecular identification methods. A total number of seven samples were collected including three milk samples and one urine sample from camel and three milk samples from buffalo. Lactobacilli were isolated by growing the bacterial contents of the samples on MRS medium as selective medium. The bacterial colonies were initially identified as Lactobacilli based on being Gram-positive and Catalase-negative as well as being rod-shaped under the microscope. Mixed colonies of each sample in MRS broth medium were used to extract DNA for molecular identification using 16S rRNA multiplex PCR analysis. The mixed colonies of each sample were also used to test antibiotic susceptibility and antibacterial activity of the isolated strains.

\section{Multiplex PCR analysis}

The results from 16S rRNA multiplex PCR analysis have been demonstrated in figure 1. A total number of 18 isolated bacteria from buffalo milk, camel milk, and camel urine were identified as Lactobacilli. Lactobacillus species were identified based on the size of the PCR product (Kwon et al., 2004). The results indicated that buffalo and camel milk were different in their Lactobacilli content. There were also differences in Lactobacilli content of different milk samples collected from the same species. The results indicated the presence of L. casei, L. acidophilus, L. rhamnosus, L. plantarum, L. gasseri and L. delbrueckii in buffalo milk samples. Meanwhile, both camel milk and camel urine samples expressed the presence of L. casei, L. acidophilus and L. plantarum.

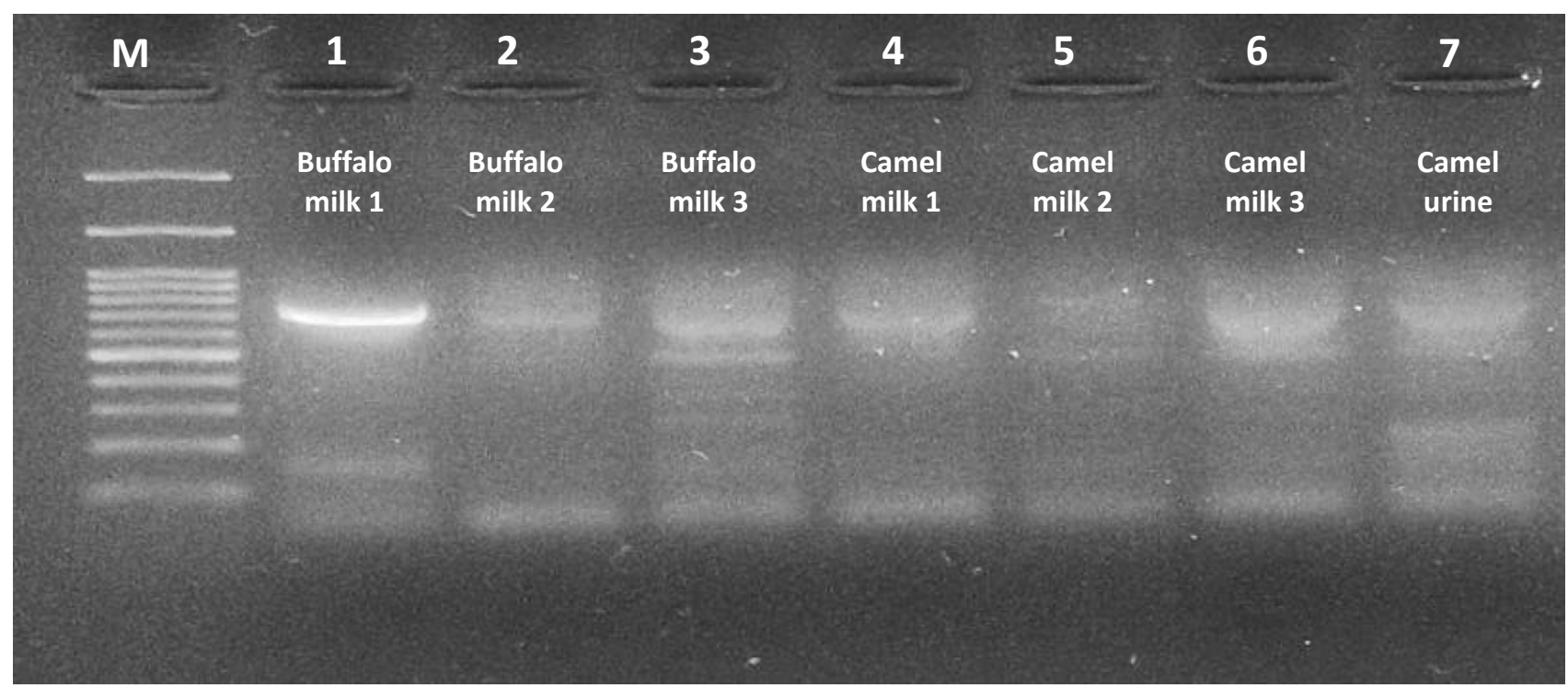

Figure 1. Agarose gel electrophoreses of PCR products from multiplex PCR assays. Multiplex PCR assays were performed with a mixture of seven species-specific or group-specific primers for L. acidophilus, L. bulgaricus (same as L. delbrueckii subsp. bulgaricus), L. casei-group L. gasseri, L. plantarum, L. reuteri and L. rhamnosus and two bacterial conserved primers. Lanes 1-7 designate the PCR product from each genomic DNA extracted from single or mixed cell suspension isolated from representative host used as PCR template. Lane 1: L. casei, L. delbrueckii; lane 2: L. casei; lane 3: L. casei, L. acidophilus, L. rhamnosus, L. plantarum and L. gasseri; lane 4: L. casei; lane 5: L. plantarum; Lane 6: L. plantarum; lane 7: L. plantarum; lane M: 100 bp-DNA ladder.

\section{Antibiotic susceptibility of Lactobacilli}

Antibiotic susceptibility of Lactobacillus strains was tested by using a panel of 14 antibiotics (Figures 2-8). It was clear that all samples had extremely significant resistant $(\mathrm{p}<0.0001)$ to Cefadroxil $(\mathrm{CFR}-30)$ with inhibition zones of $0.0 \mathrm{~cm}$. Cefaclor (CEC-30) exclusively did not present any inhibition to the growth of one of buffalo milk samples (buffalo milk 2) and all camel milk and urine samples. While Vancomycin (Va-30) did not cause any inhibition to only one of buffalo milk samples (buffalo milk 1). The rest of antibiotics exclusively presented no inhibition to camel samples which included Cefuroxime (CXM-30), Cefotaxime (CTX-30), Erythromycin (E-15), Ampicillin with sulbactam (SAM20), and Azithromycin (AZM-15). Furthermore, camel urine sample was the only one to be totally resistant to (AmC-30) 


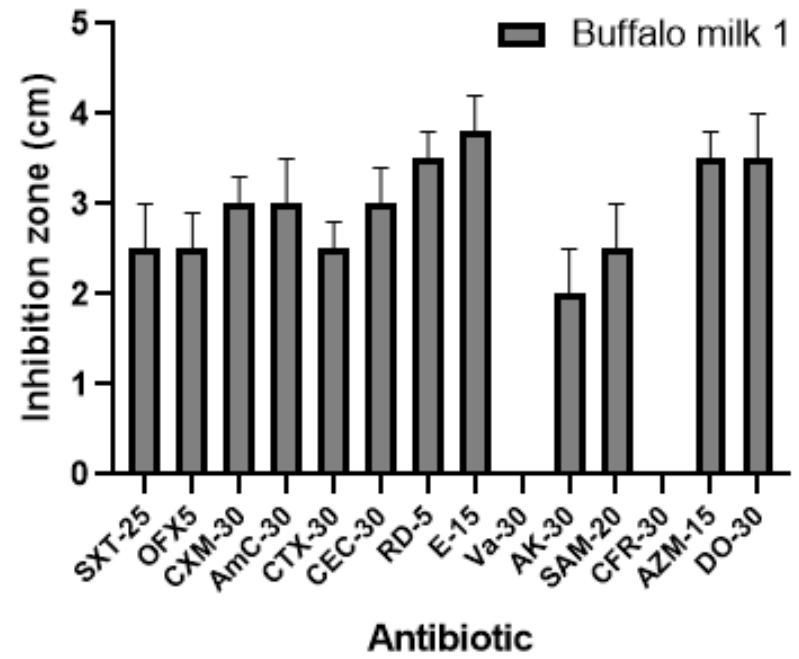

Figure 2

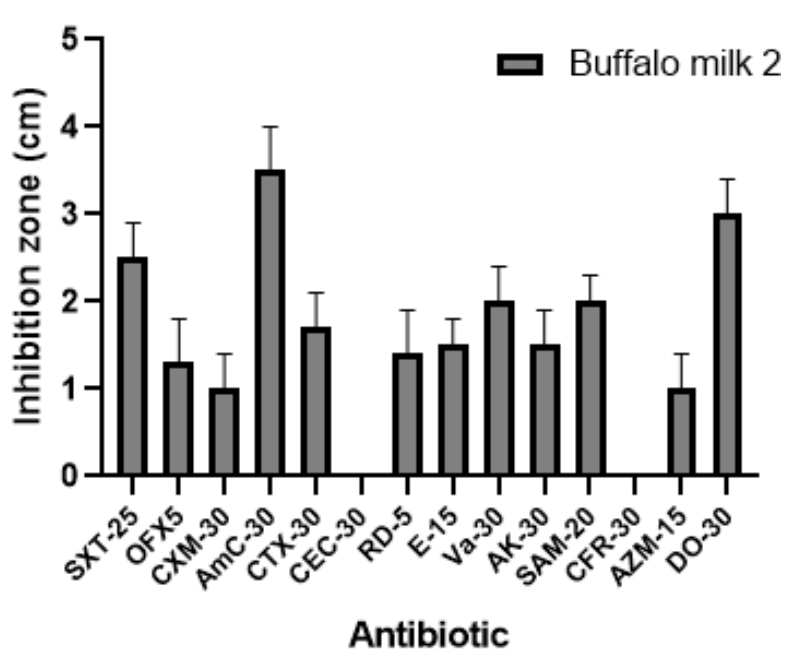

Figure 3

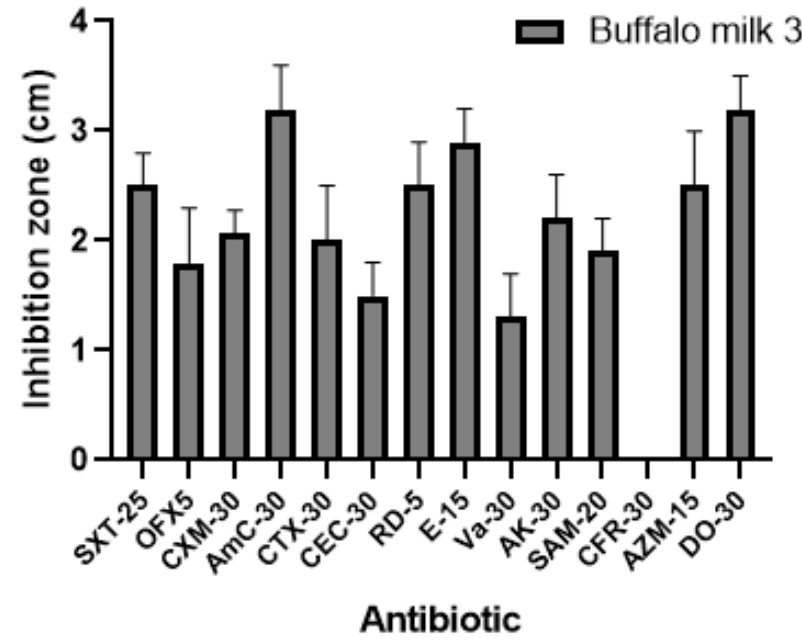

Figure 4

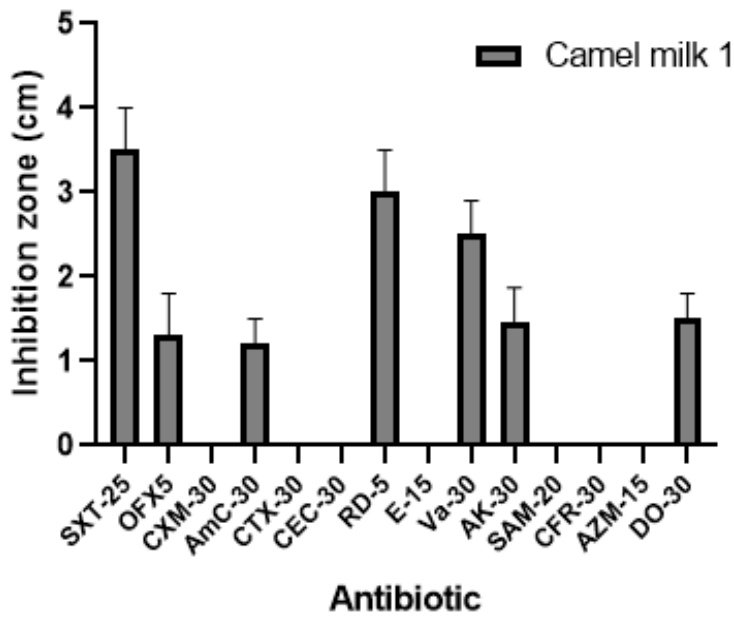

Figure 5

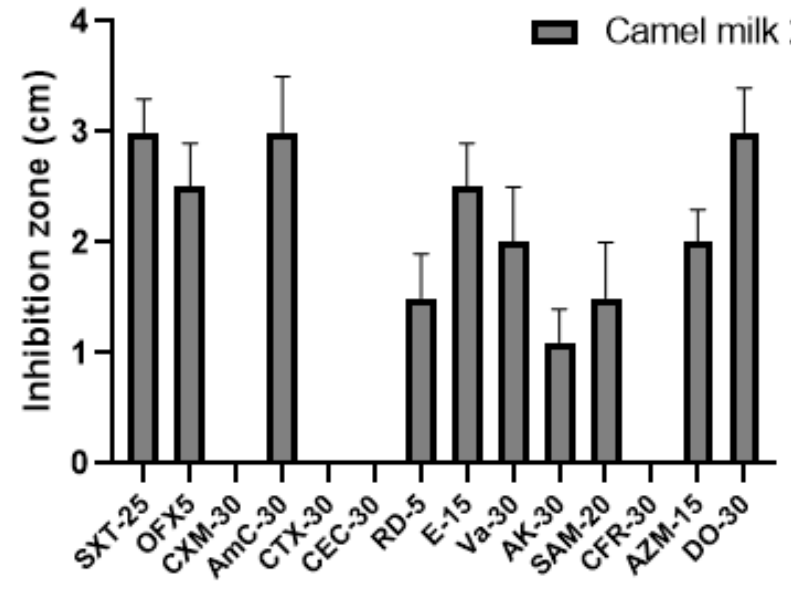

Antibiotic

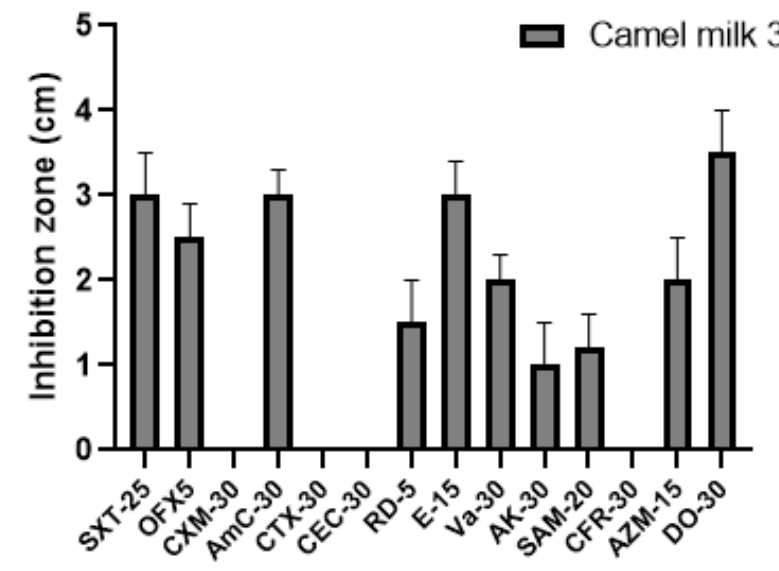

Antibiotic 


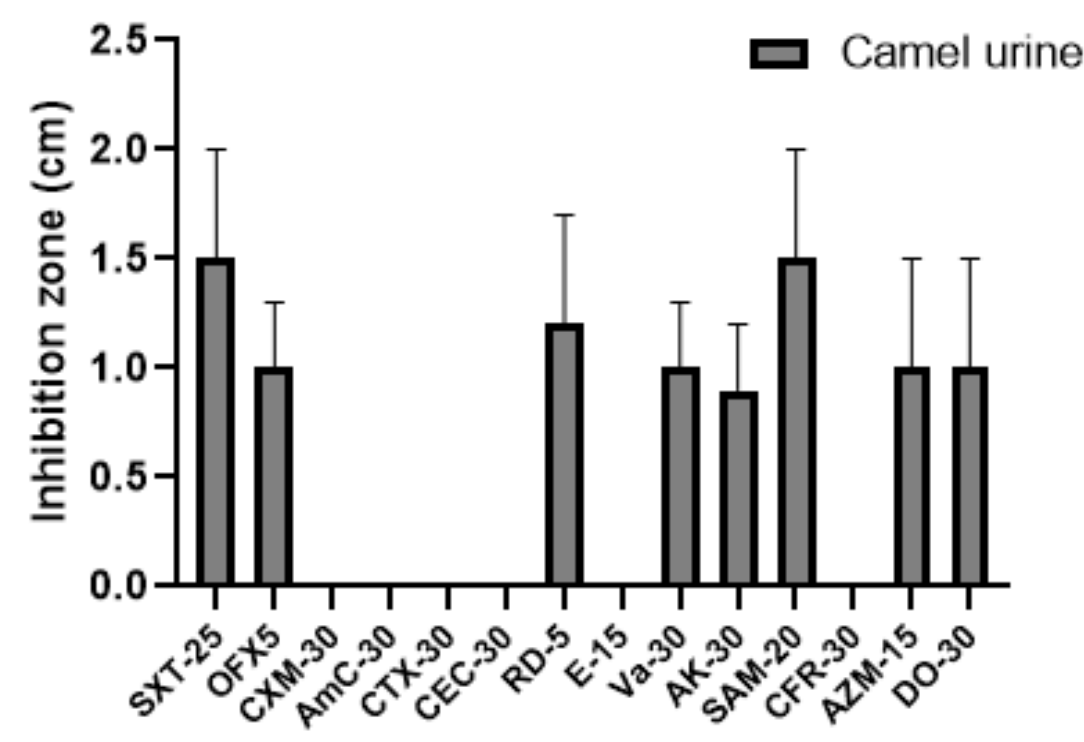

Antibiotic

Figure 8

Figures 2-8. Antibiotic susceptibility of the probiotic Lactobacilli isolated from buffalo milk, camel milk or camel urine. Fourteen antibiotic disks were used for the susceptibility test including Trimethoprim/sulfamethoxazole (SXT-25), Ofloxacin (OFX5), Cefuroxime (CXM-30), Amoxicillin with clavulanic acid (AmC-30), Cefotaxime (CTX-30), Cefaclor (CEC-30), Rifampicin (RD-5), Erythromycin (E-15), Vancomycin (Va-30), Amikacin (AK-30), Ampicillin with ctam (SAM-20), Cefadroxil (CFR-30), Azithromycin (AZM-15), and Doxycycline (DO-30).

\section{Antibacterial activity of Lactobacilli}

The antibacterial activity of the isolated probiotic Lactobacilli was investigated against nine pathogenic standard strains of both Gram- positive and Gram- negative bacteria (Figures 9-15). The results indicated that the antibacterial activity of Lactobacilli which were isolated from camel urine was in general extremely significant lower $(\mathrm{p}<0.0001)$ than the antibacterial activity of Lactobacilli from both buffalo milk and camel milk against all tested bacterial strains. The antibacterial effect of buffalo milk three was significantly higher $(\mathrm{P}=0.0045)$ than all other samples against $E$. coli 25922 while the antibacterial activity of camel milk two was significantly higher against $S$. aureus $29213(\mathrm{P}=0.0014)$, S. pneumonia $29619(\mathrm{P}=0.0014)$ and E. faecalis $29212(\mathrm{P}=0.0014)$ when compared to its effect against E. coli 10536.

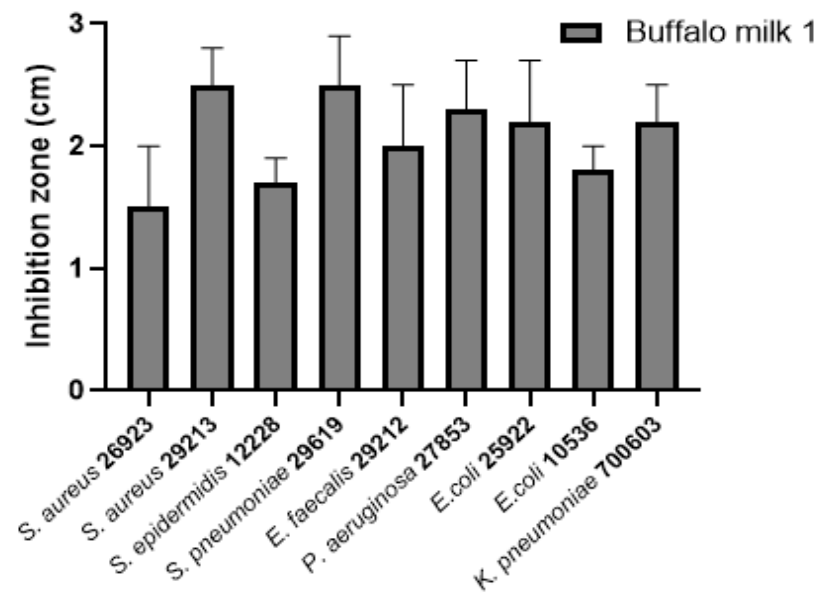

Pathogenic Bacteria

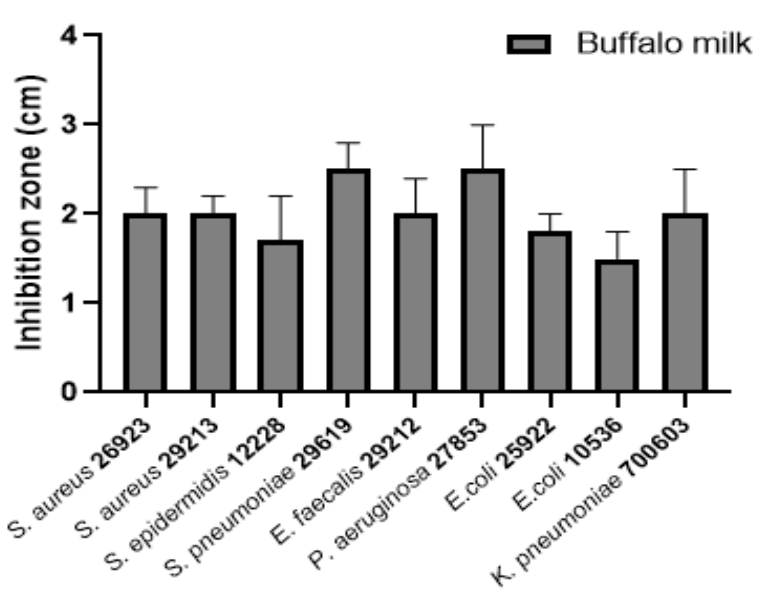

Pathogenic Bacteria

Figure 9 


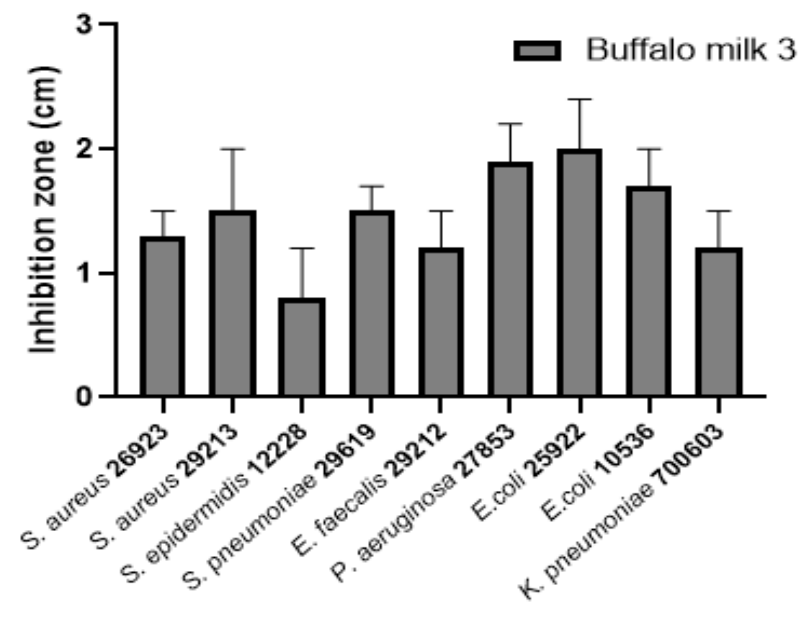

Pathogenic Bacteria

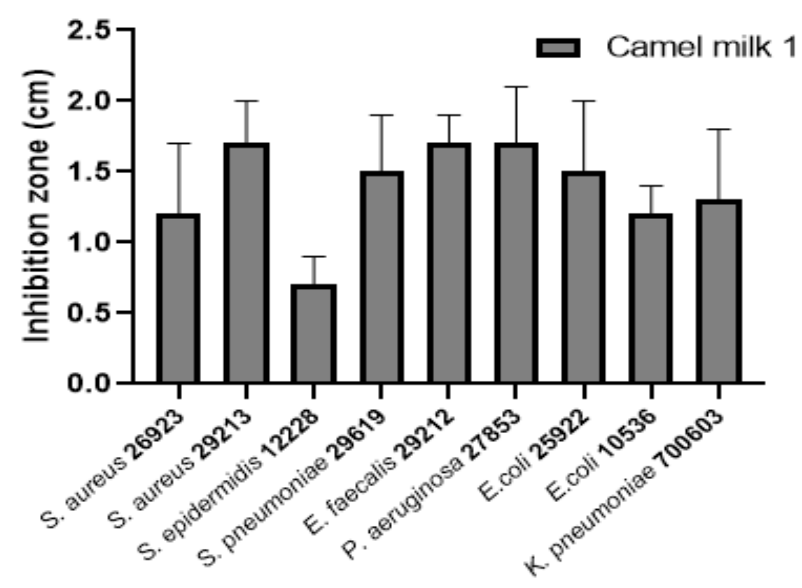

Pathogenic Bacteria

Figure 11

Figure 12

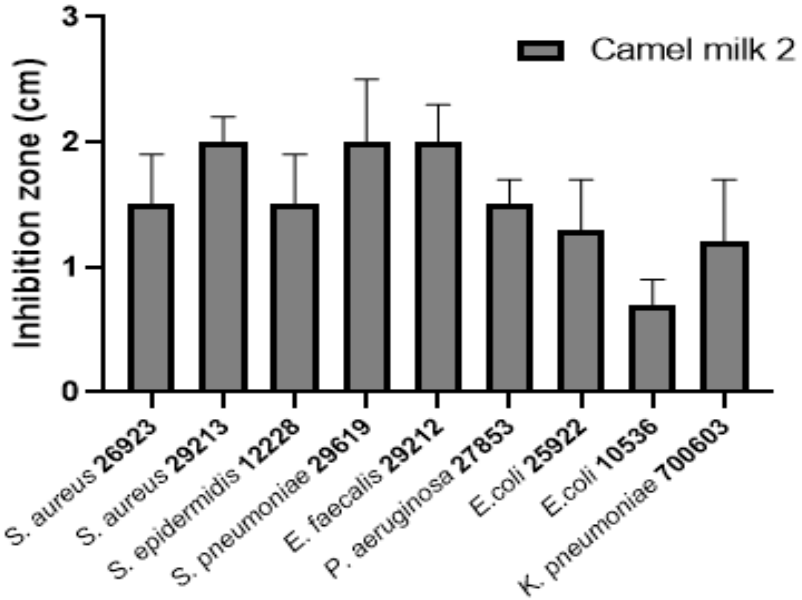

Pathogenic Bacteria

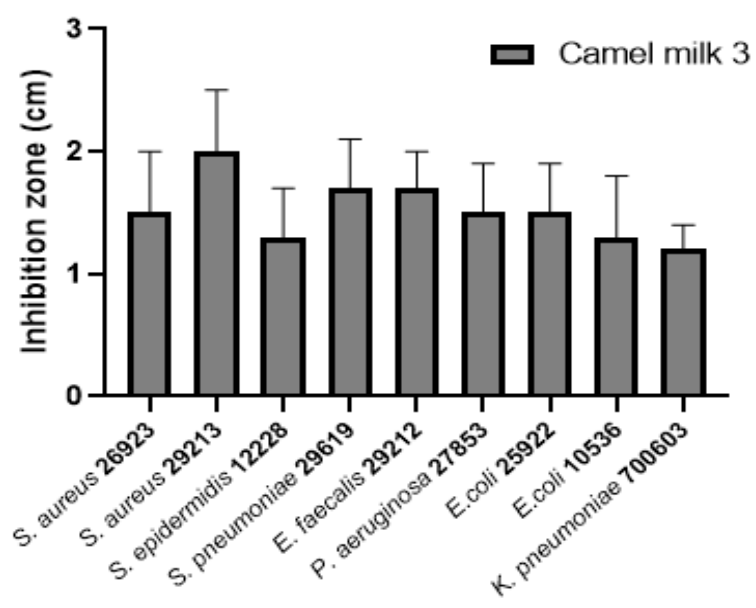

Pathogenic Bacteria

Figure 13

Figure 14

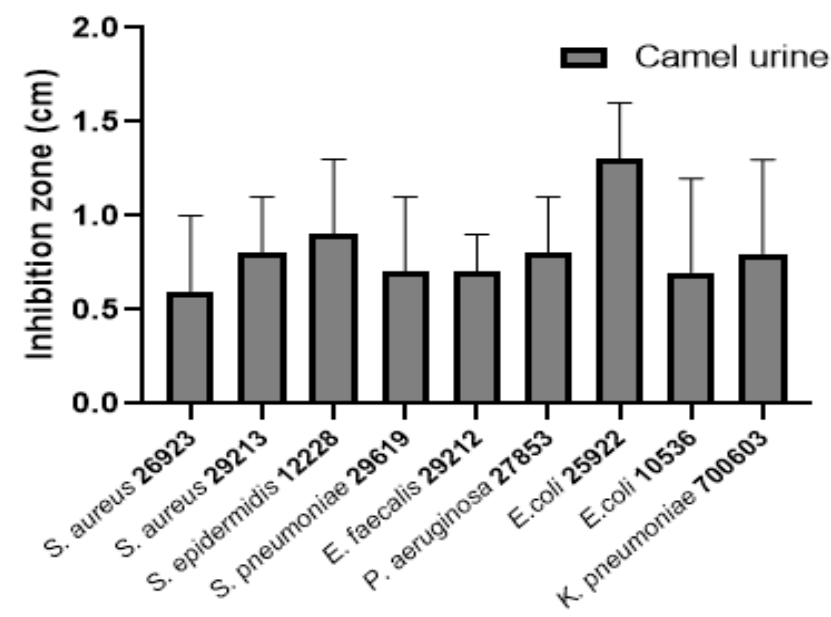

Pathogenic Bacteria

Figure 2

Figures 9-15: The antibacterial activity of the probiotic Lactobacilli isolated from buffalo milk, camel milk or camel urine. The antibacterial activity was investigated against both Gram-positive and Gram- negative bacteria using Agarwell diffusion method. Gram-positive strains were represented by S. aureus (ATCC 26923), S. aureus (ATCC 29213), S. epidermidis (ATCC 12228), S. pneumoniae (ATCC 29619), and E. faecalis ATCC (29212). Gram- negative strains were represented by P. aeruginosa ATCC (27853), E. coli ATCC (25922), E. coli ATCC (10536), and K. pneumoniae ATCC (700603) 
Probiotic bacteria have been recognized for their beneficial health effects in humans and animals. Their consumption in traditional food was associated with an extended life span and protection against diseases (Kechagia et al., 2013). The mechanisms of their beneficial effects include the protection against infectious disease either by direct competition with pathogenic microorganisms or by the modulation of the immune system and improving the digestion and reduction of metabolic disorders (Azad et al., 2018; Ghosh et al., 2019; Yousefi et al., 2019).

The main source of probiotics is fermented food including fermented milk, cheese and other dairy products. Probiotics are also isolated from both human and animal gastrointestinal tract. Furthermore, probiotic strains have been isolated from non-dairy fermented substrates including meat and fruits. Surprisingly, probiotic strains are also present in both human and animal milk which are originally expected to be sterile (McGuire and McGuire, 2015). These findings are consistent with the findings that breast-fed infants are less affected by gastrointestinal infections and have fewer allergies than formula-fed infants (Fontana et al., 2013). The same is also true about urine which had been thought to be sterile but after the development of sequencing techniques it was found that urine is colonized by normal flora including Lactobacillus and Streptococcus (Akgul and Karakan, 2018).

The diversity of probiotic Lactobacilli which isolated from different animal species has been documented (Abdou et al., 2018; Abdou et al., 2019). This diversity is the result of several factors including nutrition, infections, antibiotics, stress and various disease conditions. The variety of probiotic strains causes different types of benefits for the host.

It was clear from present findings that Lactobacilli strains isolated from both camel milk and camel urine were more resistant to the effect of antibiotics than Lactobacilli isolated from buffalo milk. This could be useful for restoring the gut microbiota after antibiotic treatment (Gueimonde et al., 2013). Although all Lactobacilli strains found in both camel milk and camel urine were also found in buffalo milk, the first two presented more resistance in general to antibiotic. This could be due to the acquisition of plasmids from other bacteria (Gueimonde et al., 2013). Camel milk and urine have been used in traditional medicine for several years to treat many diseases (Hu et al., 2017). In spite of the popularity of buffalo and cow milk and their preference among general public, camel milk is a very important replacement in arid and semi-arid areas where buffalo and cow milk are lacking. The camel milk investigation for bacterial content found it to be rich in LAB (Bin Masalam et al., 2018). In current study buffalo and camel milk were different in their Lactobacilli content. This difference might be due to the difference in milk composition (Yoganandi et al., 2014), which may allow the growth of different lactobacillus strains. Lactobacillus plantarum was isolated from camel milk and it is one of the frequently isolated LAB from raw camel milk (Khedid et al., 2009; Edalati et al., 2019).

Probiotic Lactobacilli have the potential to be used as natural alternatives to currently used synthetic antibiotics due to their antagonistic activity against various pathogenic bacteria (Prabhurajeshwar and Chandrakanth, 2017). In current study, it has been indicated that Lactobacilli isolated from buffalo milk, camel milk as well as camel urine presented variable degrees of antibacterial activity against pathogenic bacteria. Although present data indicated that isolated Lactobacilli from camel urine had the least antibacterial activity when compared to both buffalo and camel milk, the antibacterial, antifungal and antiviral activity of both camel milk and urine were reported previously (Al-Bashan, 2011; $\mathrm{Hu}$ et al., 2017). One of the reasons for the least antibacterial activity of camel urine could be using only one sample of it. The antibacterial activities of camel milk and urine in general may be partly due to the presence of different probiotic Lactobacilli including Lactobacillus plantarum and Lactobacillus casei which had been found earlier to represent promising antimicrobial activity (Bin Masalam et al., 2018).

\section{CONCLUSION}

The present study indicated the variability in contents of lactobacillus strains which isolated from buffalo milk, camel milk, and camel urine. Although some strains were similar among these samples, they presented different susceptibility to antibiotics and had different antibacterial activity against pathogenic bacteria. Further studies should be conducted with more samples to gain more information in the field of antibacterial activity of probiotic lactobacilli and to understand the mechanisms of their activity. Hopefully, they will be used as natural alternatives instead of synthetic antibiotics.

\section{DECLARATIONS}

\section{Authors' contributions}

Amr M. Abdou participated in the molecular identification of probiotic strains, performed the statistical analysis and drafted the manuscript. Riham H. Hedia participated in characterization of isolated bacteria, molecular identification of probiotic strains and antibiotic susceptibility of Lactobacilli. Shimaa T. Omara participated in characterization of isolated bacteria, molecular identification of probiotic strains, and antibacterial activity of Lactobacilli. Mai M. Kandil 
participated in sample collection and participated in the molecular identification of probiotic strains. M. A. Bakry participated in sample collection and characterization of isolated bacteria. Mohammad M. Effat proposed the idea of current study, and participated in its design and coordination and helped to draft the manuscript. All authors read and approved the final manuscript.

\section{Competing interests}

The authors declared that they had no competing interests.

\section{REFERENCE}

Abdou AM, Fouad EA, Alam SS, and Hakim AS (2019). Isolation and Identification of Probiotic Lactobacilli from Non-ruminant Animals. International Journal of Veterinary Science, 8(4): 349-354. Available at: http://www.ijvets.com/.../349-354.pdf

Abdou AM, Hedia RH, Omara ST, Mahmoud MAE, Kandil MM, and Bakry MA (2018). Interspecies comparison of probiotics isolated from different animals. Veterinary World, 11: 227-230. DOI: https://doi.org/10.14202/vetworld.2018.227-230

Akgul T, and Karakan T (2018). The role of probiotics in women with recurrent urinary tract infections. Turkish Journal of Urology, 44 : $377-383$. DOI: https://doi.org/10.5152/tud.2018.48742

Al-Bashan MM (2011). In vitro Assessment of the Antimicrobial Activity and Biochemical Properties of Camel's Urine Against Some Human Pathogenic Microbes. Middle-East Journal of Scientific Research, 7: 947-958. Available at: https://bengreenfieldfitness.com/wpcontent/uploads/2017/02/In-vitro-Assessment-of-the-Antimicrobial-Activity-and-Biochemical-Properties-of-camels-urine.pdf

Azad MAK, Sarker M, and Wan D (2018). Immunomodulatory Effects of Probiotics on Cytokine Profiles. BioMed Research International, 2018: 8063647. DOI: https://doi.org/10.1155/2018/8063647

Bauer AW, Kirby WM, Sherris JC, and Turck M (1966). Antibiotic susceptibility testing by a standardized single disk method. American Journal of Clinical Pathology, 45(4): 493-496. DOI: https://doi.org/10.1093/ajcp/45.4_ts.493

Bergey DHJ, John GH, Noel RK, and Peter HAS (1994). Bergey’s Manual of Determinative Bacteriology, 9 th ed. Avaliable at:

https://books.google.com.eg/books?id=jtMLzaa5ONcC\&printsec=frontcover\&hl=ar\&source=gbs_ge_summary_r\&cad=0\#v=onepage\&q\&f=false

Bin Masalam MS, Bahieldin A, Alharbi MG, Al-Masaudi S, Al-Jaouni SK, Harakeh SM, and Al-Hindi RR (2018). Isolation, Molecular Characterization and Probiotic Potential of Lactic Acid Bacteria in Saudi Raw and Fermented Milk. Evidence-Based Complementary and Alternative Medicine, 2018, 7970463. DOI: https://doi.org/10.1155/2018/7970463

Brunel AS, and Guery B (2017). Multidrug resistant (or antimicrobial-resistant) pathogens - alternatives to new antibiotics? Swiss Medical Weekly, 147: w14553. DOI: https://doi.org/10.4414/smw.2017.14553

Davies J, and Davies D (2010). Origins and evolution of antibiotic resistance. Microbiology and Molecular Biology Reviews, 74: 417-433. DOI: https://doi.org/10.1128/MMBR.00016-10

Edalati E, Saneei B, Alizadeh M, Hosseini SS, Zahedi Bialvaei A, and Taheri K (2019). Isolation of probiotic bacteria from raw camel's milk and their antagonistic effects on two bacteria causing food poisoning. New Microbes and New Infections, 27: 64-68. DOI: https://doi.org/10.1016/j.nmni.2018.11.008

FAO/WHO (2011). ICMR-DBT guidelines for evaluation of probiotics in food. Indian Journal of Medical Research, 134(1): 22-25. Available at: https://www.ncbi.nlm.nih.gov/pmc/articles/PMC3171912/

Fijan S (2014). Microorganisms with claimed probiotic properties: an overview of recent literature. Int International Journal of Environmental Research and Public Health, 11(5): 4745-4767. https://doi.org/10.3390/ijerph110504745

Fontana L, Bermudez-Brito M, Plaza-Diaz J, Munoz-Quezada S, and Gil A (2013). Sources, isolation, characterisation and evaluation of probiotics. British Journal of Nutrition, 109 Suppl 2: S35-50. DOI: https://doi.org/10.1017/S0007114512004011

Ghosh T, Beniwal A, Semwal A, and Navani NK (2019). Mechanistic Insights Into Probiotic Properties of Lactic Acid Bacteria Associated With Ethnic Fermented Dairy Products. Frontiers in Microbiology, 10: 502. DOI: https://doi.org/10.3389/fmicb.2019.00502

Gueimonde M, Sánchez B, G de Los Reyes-Gavilán C, and Margolles A (2013). Antibiotic resistance in probiotic bacteria. Frontiers in microbiology, 4, 202. https://doi.org/10.3389/fmicb.2013.00202

Hao Q, Lu Z, Dong BR, Huang CQ, and Wu T (2011). Probiotics for preventing acute upper respiratory tract infections. Cochrane Database of Systematic Reviews, CD006895. DOI: https://doi.org/10.1002/14651858.CD006895.pub2

Hu Z, Chang X, Pan Q, Gu K, and Okechukwu PN (2017). Gastroprotective and Ulcer Healing Effects of Camel Milk and Urine in HC1/EtOH, Nonsteroidal Anti-inflammatory Drugs (Indomethacin), and Water-Restraint Stress-induced Ulcer in Rats. Pharmacognosy Magazine, 13: 559-565. DOI: https://doi.org/10.4103/pm.pm_135_17

International Organization for Standardization (ISO) (2010). Milk and milk products_-determination of the minimal inhibitory concentration (MIC) of antibiotics applicable to bifidobacteria and non-enterococcal lactic acid bacteria (LAB). ISO 10932/IDF 233 standard. Available at: https://www.iso.org/standard/46434.html

Kechagia M, Basoulis D, Konstantopoulou S, Dimitriadi D, Gyftopoulou K, Skarmoutsou N, and Fakiri EM (2013). Health benefits of probiotics: a review. ISRN Nutrition, Article ID: 481651. DOI: https://doi.org/10.5402/2013/481651

Khedid K, Faid M, Mokhtari A, Soulaymani A, and Zinedine A (2009). Characterization of lactic acid bacteria isolated from the one humped camel milk produced in Morocco. Microbiological Research, 164: 81-91. DOI: https://doi.org/10.1016/j.micres.2006.10.008

Kwon HS, Yang EH, Yeon SW, Kang BH, and Kim TY (2004). Rapid identification of probiotic Lactobacillus species by multiplex PCR using species-specific primers based on the region extending from 16S rRNA through 23S rRNA. FEMS Microbiology Letters, 239: 267-275. DOI: https://doi.org/10.1016/j.femsle.2004.08.049

McGuire MK, and McGuire MA (2015). Human milk: mother nature's prototypical probiotic food? Adv Nutr. Jan 15; 6(1): 112-123. DOI: https://doi.org/10.3945/an.114.007435.

Ozen M, Kocabas Sandal G, and Dinleyici EC (2015). Probiotics for the prevention of pediatric upper respiratory tract infections: a systematic review. Expert Opinion on Biological Therapy, 15: 9-20. DOI: https://doi.org/10.1517/14712598.2015.980233

Prabhurajeshwar C, and Chandrakanth RK (2017). Probiotic potential of Lactobacilli with antagonistic activity against pathogenic strains: An in vitro validation for the production of inhibitory substances. Biomedical journal, 40(5): 270-283. DOI: https://doi.org/10.1016/j.bj.2017.06.008

To cite this paper: Abdou AM, Hedia RH, Omara ST, Kandil MM, Bakry MA and Effat MM (2021). Microbiological Studies on Naturally Present Bacteria in Camel and Buffalo Milk. World Vet. J., 10 (4): 562-570. DOI: https://dx.doi.org/10.54203/scil.2020.wvj67 
Ruiz Rodriguez LG, Mohamed F, Bleckwedel J, Medina R, De Vuyst L, Hebert EM, and Mozzi F (2019). Diversity and Functional Properties of Lactic Acid Bacteria Isolated From Wild Fruits and Flowers Present in Northern Argentina. Frontiers in Microbiology, 10: 1091. DOI: https://doi.org/10.3389/fmicb.2019.01091

Sgouras D, Maragkoudakis P, Petraki K, Martinez-Gonzalez B, Eriotou E, Michopoulos S, Kalantzopoulos G, Tsakalidou E, and Mentis A (2004). In vitro and in vivo inhibition of Helicobacter pylori by Lactobacillus casei strain Shirota. Applied and Environmental Microbiology, 70(1): 518526. DOI: https://doi.org/10.1128/aem.70.1.518-526.2004

Shokryazdan P, Sieo CC, Kalavathy R, Liang JB, Alitheen NB, Faseleh Jahromi M, and Ho YW (2014). Probiotic potential of Lactobacillus strains with antimicrobial activity against some human pathogenic strains. BioMed Research International, 927268. DOI: https://doi.org/10.1155/2014/927268

Steel RGD, and Torrie JH (1980). Principles and Procedures of Statistics. 2nd ed. McGraw Hill Book Company, New York.

Williams MD, Ha CY, and Ciorba MA (2010). Probiotics as therapy in gastroenterology: a study of physician opinions and recommendations. Journal of Clinical Gastroenterology, 44: 631-636. DOI: https://doi.org/10.1097/MCG.0b013e3181d47f5b

Yoganandi J, Mehta BM, Wadhwani KN, Darji VB, and Aparnathi KD (2014). Evaluation and Comparison of Camel Milk with Cow Milk and Buffalo Milk for Gross Composition. Journal of Camel Practice and Research, 21(2): 259-265. DOI: https://doi.org/10.5958/2277-8934.2014.00046.0

Yousefi B, Eslami M, Ghasemian A, Kokhaei P, Salek Farrokhi A, and Darabi N (2019). Probiotics importance and their immunomodulatory properties. Journal of Cellular Physiology, 234 (6): 8008-8018. DOI: https://doi.org/10.1002/jcp.27559 